\title{
"Is there a doctor on board?": Practical recommendations for managing in-flight medical emergencies
}

\author{
David Kodama MD MSc, Bobby Yanagawa MD PhD, Jim Chung MD MAvMed, Ken Fryatt MD, Alun D. Ackery MD MSc
}

Cite as: CMAJ 2018 February 26;190:E217-22. doi: 10.1503/cmaj.170601

H

earing the call go out for a doctor at 36000 feet can be anxiety-provoking for any physician. If health professionals offer their expertise, they may have to manage an unfamiliar clinical scenario, in a foreign and limited environment, without knowledge of the available resources. Passengers who are health care professionals, along with members of the flight crew, are often important resources for in-flight front-line care. Although flight crews receive some training in the treatment of in-flight medical emergencies, health care professionals receive little to none. They may be unaware of the medical equipment on board and the environmental challenges of treating patients on an aircraft. Furthermore, they may be unfamiliar with the airline's policies and procedures and their legal and ethical duties to respond. We review these issues to offer resources for Canadian health care practitioners who must manage inflight medical emergencies. Our search for evidence used in this review is summarized in Box 1. We draw on examples and resources from Canada's two largest air carriers, Air Canada and WestJet.

\section{What is the incidence of in-flight medical emergencies and their most common causes?}

The global airline industry continues to grow. A recent study estimated that about 2.75 billion passengers worldwide fly on commercial airlines each year. ${ }^{1}$ In Canada, there were 133.4 million airline passengers in 2015, a 27.3\% increase from 2009. ${ }^{2}$ This rise in passenger traffic is just one of the reasons why the incidence of in-flight medical emergencies is increasing. ${ }^{3}$ Another important cause is longer flight durations, which subjects passengers to longer exposure to physiologic stressors, including relative hypoxia and lower relative humidity. ${ }^{3-5}$ These stressors may have greater effect on the increasing proportion of older passengers and those flying with pre-existing medical conditions. ${ }^{6-8}$

The true incidence of in-flight medical emergencies is difficult to determine, as there is no consensus on what defines an inflight "emergency," no agreed-upon classification system, no mandate for airlines to collect or report these events and, therefore, no reliable database of information..$^{8-10}$ One recent study of

\section{KEY POINTS}

- Medical professionals who voluntarily provide emergency medical assistance on a commercial aircraft are protected from liability.

- The cabin environment will affect patients' vital signs as well as how to measure them reliably - e.g., normal oxygen saturation at $6000-8000 \mathrm{ft}(1829-2438 \mathrm{~m})$ is about $90 \%$ and aircraft noise may limit the usefulness of a stethoscope.

- Most of the medications in the medical kit can be administered via the intramuscular route; the administration of intravenous epinephrine should not be used for any indication other than cardiac arrest, unless the medical professional is comfortable doing so or it is done under the advice of the ground-based consultant. The working environment should be optimized by creating space, turning on the cabin lights and recruiting additional help. Flight attendants should provide the medical kit and contact ground-based telemedicine support early.

- Open, two-way communication with the flight attendants, cockpit and ground-based consultants should be maintained to ensure the pilots can make the safest decisions for all of the passengers.

data from a ground-based medical consultation company that serviced five different North American airlines estimated an incidence of 1 medical emergency per 604 flights (or 16 events per 1 million passengers). ${ }^{1}$ In contrast, a European study of medical records from a single airline over a two-year period reported 1312 events among 10.1 million passengers, or the equivalent of roughly 1:7700 passengers. ${ }^{11}$ The UK government analyzed data from the Aerospace Medical Association, British Air Transportation Association and a ground-based consultant company to report an incidence of 1 event per 14000 passengers but notes substantial difficulties in establishing the true incidence, given the lack of consistency between data sets. ${ }^{12}$ For the same reasons that establishing the true incidence of in-flight emergencies is challenging, so too is determining the causes of these events. The most recent data from a robust North American study found the top five causes of in-flight medical emergencies to be "syncope/presyncope" (37.4\%), "respiratory symptoms" (12.1\%), "nausea or vomiting" (9.5\%), "cardiac symptoms" (7.7\%) and "seizures" (5.8\%). ${ }^{1}$ 


\section{Box 1: Evidence used in this review}

We searched MEDLINE and PubMed databases using the terms "aerospace medicine," "emergency," "in-flight" and "medical." We used the "related articles" function to further identify relevant resources and restricted our search to articles published in English only. We also searched Google databases to locate relevant information pertaining to Transport Canada regulations, current Canadian medicolegal responsibilities, and international aviation standards and regulations through the International Civil Aviation Organization and Aerospace Medical Association. Access to medical kits and information on WestJet's and Air Canada's policies, procedures and incident data were obtained through direct communication with the chief medical officers of both organizations. Finally, we obtained information pertaining to the policies and procedures of ground-based consultants via telephone interview with the Global Medical Director of MedAire, Inc. in Phoenix, Ariz.

\section{What medical resources are available on board Canadian commercial aircraft?}

According to Transport Canada, any aircraft with at least 100 passenger seats is legally required to carry a medical kit (in addition to the usual standard first aid kit). ${ }^{13}$ Aircraft with fewer than 100 seats are required to carry only a standard first aid kit. Transport Canada outlines the minimal requirements the medical kit must contain. However, airlines have the flexibility to enhance the contents as they see fit, and often do so using the guideline from the International Civil Aviation Organization. ${ }^{14}$ Table 1 illustrates Transport Canada regulations (Figure 1) compared with what is available on board Air Canada and West Jet aircraft (Figure 2; a video is also available in Appendix 1 [www.cmaj.ca/ lookup/suppl/doi:10.1503/cmaj.170601/-/DC1] with a guide to Air Canada's in-flight emergency medical kit). Other important resuscitative equipment on board commercial aircraft includes supplemental oxygen canisters, the number of which will vary depending on the size of the aircraft. In Canada, automated external defibrillators are currently not mandatory; however, Air Canada and WestJet have voluntarily stocked them on most of their aircraft. It is important to remember that patients often carry their own medications, which can be used alone or in combination with medications from the medical kit.

\section{Medical equipment}

It is important to be aware of and understand the strengths and limitations of the medical equipment on board commercial aircraft when managing in-flight medical emergencies. A common complaint in Air Canada incident reports is that the medical kit's stethoscope is either "broken" or "doesn't work." However, in a loud aircraft cabin, performing auscultation for breath sounds or taking blood pressure measurements can be challenging, if not impossible. ${ }^{15}$ Confirming systolic blood pressure by palpating the radial artery as the cuff deflates, or by watching for the return of the waveform if using a pulse oximeter, are more practical methods of measuring blood pressure in a noisy aircraft cabin.
Oxygen canisters are connected to a mask with a reservoir bag, which looks similar to those that drop during depressurization events. Although this is technically a "nonrebreather" type of mask, the flow rates of the oxygen canisters can be set only to either low flow $(2 \mathrm{~L} / \mathrm{min})$ or high flow $(4 \mathrm{~L} / \mathrm{min})$. It is important to note that even at high flow, a fraction of inspired oxygen $\left(\mathrm{FiO}_{2}\right)$ of $100 \%$ will not be attainable when administering supplemental oxygen.

Air Canada includes a pulse oximeter in its medical kits. Aircraft cabins are pressurized to an elevation between 6000 and 8000 feet (1829 m and $2438 \mathrm{~m}$ ). At these altitudes, passengers experience a relative hypoxia, resulting in a normal oxygen saturation of about $90 \% .4,5$ This natural change in physiology, along with the aforementioned limitations of supplemental oxygen delivery, are important to consider when examining and managing patients, as well as proposing a differential diagnosis when on board an aircraft.

\section{Medications}

Many health care professionals may not be familiar with available medication preparations. Most in-flight kit medications are available in stand-alone ampules or vials. For professionals who are not accustomed to reconstituting or drawing up their own medications, this adds another layer of complexity in an already stressful situation and may contribute to errors in dosing or delivery route. Even establishing intravenous access can be a challenge owing to a combination of patient factors (e.g., body habitus, edema, age), environment factors (e.g., turbulence) or health care personnel factors (e.g., lack of skill).

To help reduce error and simplify medication delivery, we have outlined which injectable medications in the Air Canada and WestJet medical kits may be administered via the intramuscular route (Table 2). In our opinion, the 1:1000 concentration of epinephrine in the medical kit is the medication that carries the highest risk of error in administration. This concentration is typically reserved for intramuscular administration for the treatment of anaphylaxis and has been stocked in the kit in lieu of epinephrine auto-injectors (e.g., an Epipen [Pfizer]). Injecting $0.3-0.5 \mathrm{~mL}$ of this concentration intravenously could have serious adverse consequences, such as arrhythmia or a hypertensive emergency. Intravenous delivery of this concentration is reserved for patients in cardiac arrest, although WestJet provides prefilled syringes of epinephrine 1:10000 for this purpose. To limit errors, we suggest that epinephrine be administered intravenously only for patients in cardiac arrest. In uncommon instances where administration of intravenous epinephrine is required in noncardiac arrest situations - e.g., refractory anaphylaxis or as a vasopressor - we suggest that unless the physician has experience with this practice, expert consultation be sought from other medical volunteers on board or from ground-based telemedicine support.

\section{People}

Fellow health care professionals with diverse skill sets and experience can assist in optimal patient management. Research has shown physicians to be the primary responder in $40 \%-50 \%$ of inflight emergencies, nurses and paramedics in 5\%-25\% of events and flight attendants alone in $45 \%$ of incidents. ${ }^{11,16}$ Air Canada 
Table 1: Transport Canada requirements for medical kits on board aircraft with at least 100 passengers ${ }^{13}$ as well as the contents of medical kits onboard applicable Air Canada and WestJet aircraft. Numbers indicate the quantity of each kit item

\begin{tabular}{|c|c|c|c|}
\hline Kit items & Transport Canada & Air Canada & WestJet \\
\hline \multicolumn{4}{|l|}{ Equipment } \\
\hline Blood pressure cuff & 1 & 1 & 1 \\
\hline Stethoscope & 1 & 1 & 1 \\
\hline Syringes & $4^{*}$ & 11 & 6 \\
\hline Needles & $6^{*}$ & 12 & 6 \\
\hline Latex gloves & 2 & 2 & 2 \\
\hline CPR mask & 1 & $3-5 \dagger$ & $3 \ddagger$ \\
\hline CPR mask valves & 2 & $3-5 \dagger$ & 2 \\
\hline Oropharyngeal airways & $3 \S$ & $4 \S$ & $6 \S$ \\
\hline Bag valve mask & 19 & 1 & 1 \\
\hline IV administration kit & $1^{\star \star}$ & $1 \dagger \dagger$ & $1 \dagger \dagger$ \\
\hline Sharps container & 1 & 1 & 1 \\
\hline Thermometer strips & & 4 & 4 \\
\hline Umbilical cord clamps & & 2 & \\
\hline Tongue depressor & & 3 & \\
\hline Glucometer & & 1 & \\
\hline Glucose test strips & & 6 & \\
\hline Burn dressing & & 1 & \\
\hline Disposable scalpel & & 1 & \\
\hline Disposable mask & & 1 & \\
\hline Oxymeter & & 1 & \\
\hline Flashlight & & 1 & \\
\hline Urinary catheter & & 1 & \\
\hline Lubricating gel & & 1 & \\
\hline \multicolumn{4}{|l|}{ Medications } \\
\hline $50 \mathrm{~mL} 50 \%$ dextrose inj & $1 \mathrm{~A}$ or equivalent & 2 vials & 1 vial \\
\hline Epinephrine 1:1000 & $4 \mathrm{~A}$ or equivalent & $6 \mathrm{~A}$ & $2 \mathrm{~A}$ \\
\hline Epinephrine 1:10 000 & & & $2 \mathrm{PFS}$ \\
\hline Diphenhydramine inj & $2 \mathrm{~A}$ or equivalent & 3 vials & $2 \mathrm{~A}$ \\
\hline Diphenhydramine tabs & & & 4 tabs \\
\hline Nitroglycerin & 10 tabs or equivalent & 1 spray bottle & 1 spray bottle \\
\hline Salbutamol & 1 inhaler or equivalent & 1 inhaler & 1 inhaler \\
\hline ASA & 4 tabs & 6 tabs & 12 tabs \\
\hline Atropine & $1 \mathrm{~A}$ or equivalent & $4 \mathrm{~A}$ & $2 \mathrm{~A} / \mathrm{PFS}$ \\
\hline Normal saline $(500 \mathrm{~mL})$ & 1 & 2 & 2 \\
\hline Diazepam & & $2 \mathrm{~A}$ & \\
\hline Dimenhydrinate & & 1 vial & \\
\hline Ondansetron & & & 4 tabs \\
\hline Furosemide & & $1 \mathrm{~A}$ & \\
\hline Haloperidol & & $2 \mathrm{~A}$ & \\
\hline Ketorolac & & 2 vials & \\
\hline Lidocaine & & $2 \mathrm{PFS}$ & \\
\hline Lorazepam & & 4 tabs & \\
\hline Loperamide & & & 4 tabs \\
\hline Methylprednisolone & & 1 vialłf & \\
\hline Acetaminophen & & & 4 tabs \\
\hline Acetaminophen pediatric bottle & & & 1 bottle \\
\hline \multicolumn{4}{|l|}{ Documents } \\
\hline Instructions for medication use & $\checkmark$ & $\checkmark$ & $\checkmark$ \\
\hline Medical kit content list & & $\checkmark$ & $\checkmark$ \\
\hline Treatment instructions & & $\checkmark \S \S$ & \\
\hline \multicolumn{4}{|c|}{ 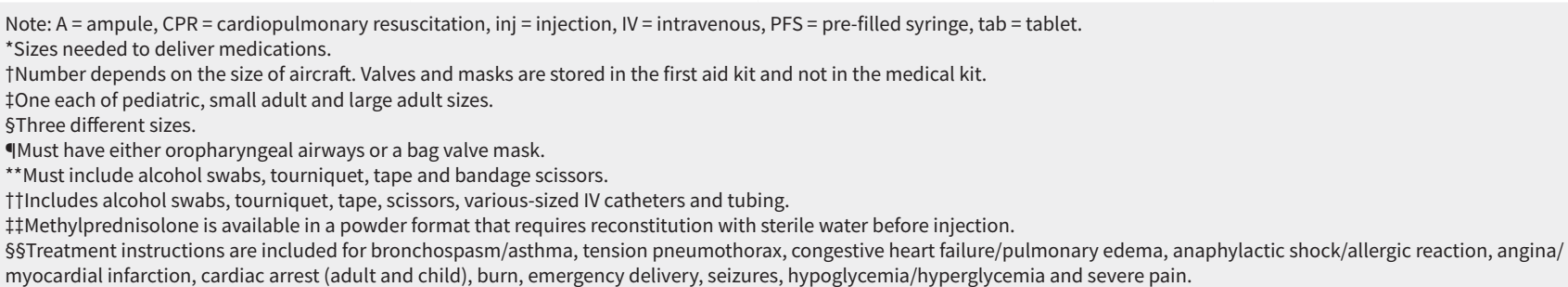 } \\
\hline
\end{tabular}


data showed that between 2014 and 2016, roughly half (49\%$53 \%$ ) of in-flight medical emergencies were managed by a physician, nurse or paramedic, with the remainder managed by flight attendants alone (unpublished observations). Not every inflight medical emergency will require a team-based approach. However, in complex clinical presentations or those that require many resources, making use of additional health care professionals may be helpful. Should multiple volunteers be present, assigning clear roles and responsibilities that play to each team member's strengths will help to ensure a smooth resuscitation.

Finally, flight attendants are a critical resource who will be involved in all in-flight emergencies. Not only are they trained in basic first aid, cardiopulmonary resuscitation and use of an automated external defibrillator, ${ }^{17}$ they are also familiar with both the aircraft and the airline emergency procedures. They are the pri- mary contact with the cockpit, can assist in recruiting additional health care volunteers and can help create sufficient space for patient management. As Peterson and colleagues outline in their approach to responding to an in-flight emergency, flight attendants should be involved early to facilitate communication with ground-based telemedicine support and to obtain the medical kit, automated external defibrillator and supplemental oxygen. ${ }^{1}$

\section{What environmental factors affect patient care during in-flight emergencies?}

The airplane cabin environment could not be more different than a typical examination room. It is cramped, loud and dim, and lacks privacy - all of which pose challenges when treating a patient. Most patients can safely be managed in their seats.

\section{A}

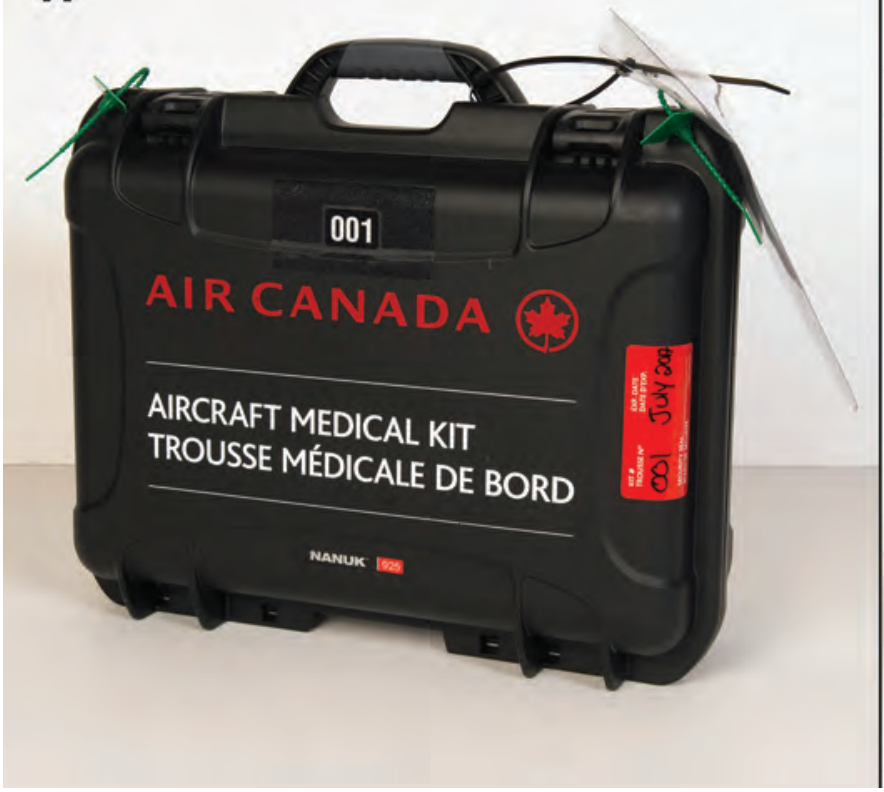

B

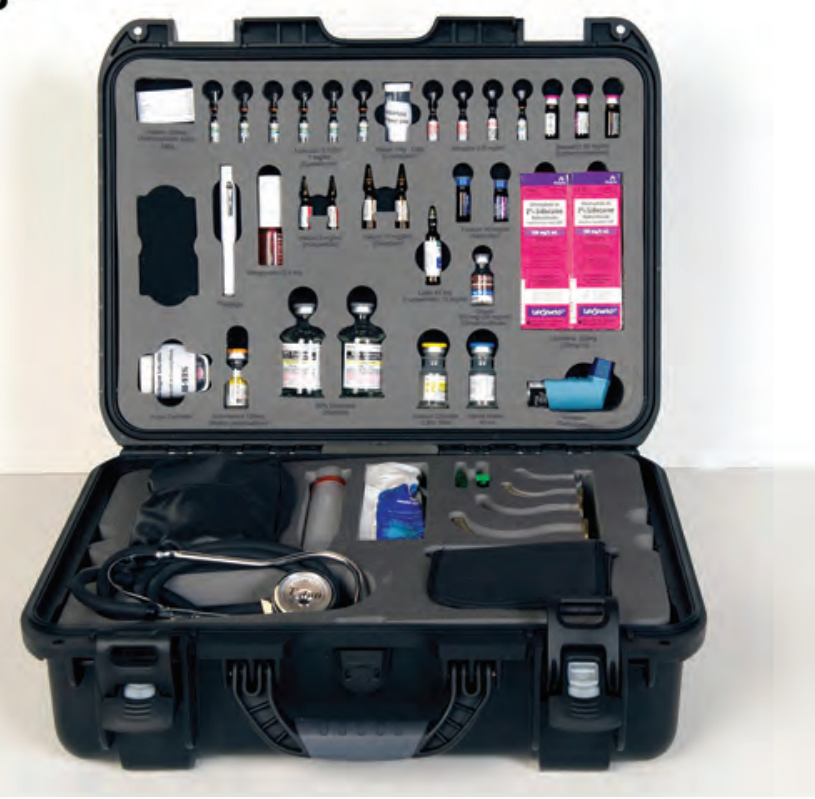

Figure 1: (A) Air Canada's on-board medical kit. (B) Medications are contained in the top tray and equipment is located in the bottom tray. There is also additional equipment underneath the bottom tray.

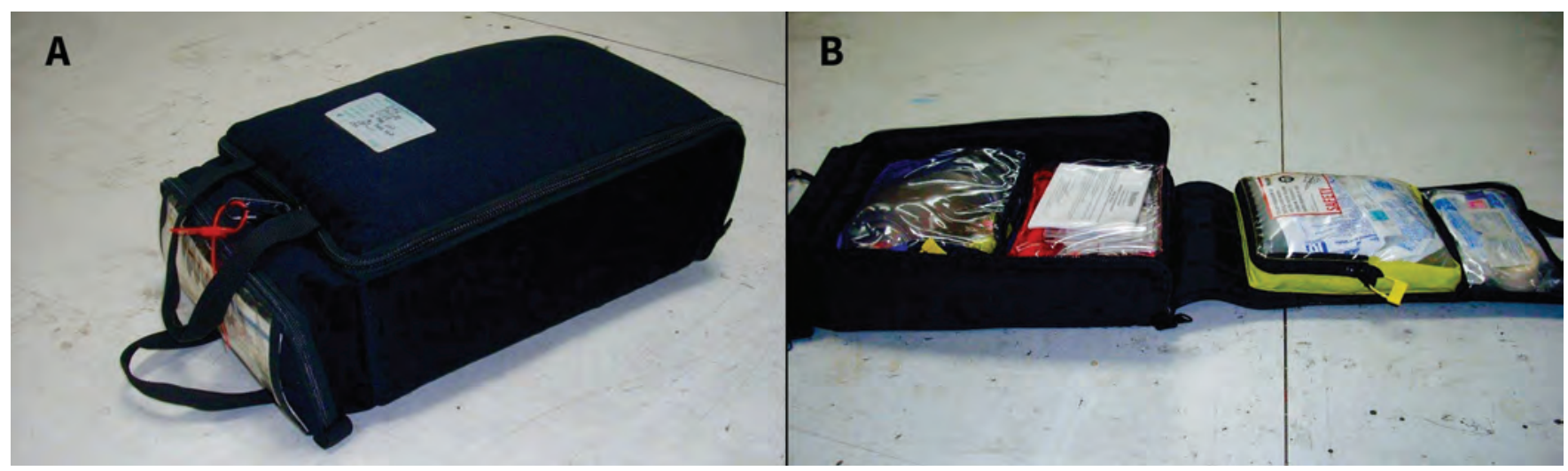

Figure 2: (A) WestJet's on-board medical kit. (B) The kit is divided into sections based on colour. The exterior of the kit contains diagnostic equipment, including the blood pressure cuff, stethoscope and thermometer strips. The yellow section contains intravenous supplies, the orange section contains medications and the blue section contains airway equipment. 
However, if the patient needs to be repositioned or more space is required for a comprehensive examination, options include asking surrounding passengers to vacate the row, placing the patient in the aisle or, perhaps most useful, transporting the patient to a more spacious area of the aircraft, such as the galley. We also recommend asking for the cabin lighting to be turned on full.

\section{What policies and procedures are in place to manage in-flight medical emergencies?}

\section{Ground support}

Ground-based medical consulting companies, such as Stat MD, Inc. (Pittsburgh) and MedAire, Inc. (Phoenix), support most major airlines, including Air Canada and WestJet, respectively. Their involvement is a part of the airline's procedures for managing inflight medical emergencies. The primary role of these telemedicine agencies is to assist in medical decision-making by supporting, advising and directing on-board medical volunteers. They also provide guidance to pilots regarding diversion decisions and can recommend optimal locations for diversion depending on the patient's status and working diagnosis.

The process for speaking with ground-based medical staff varies among airlines. For example, West Jet provides health care professional volunteers with a satellite communication device to speak directly with the ground physician. Air Canada's policy is to have a flight attendant act as the liaison between the medical volunteer and the cockpit, which is in turn in contact with the ground physician; a written telemedicine checklist is used.

\section{Aircraft diversion}

The decision to divert an aircraft depends primarily on the medical condition and stability of the patient. According to a study that reviewed American data from Jan. 1, 2008, through Oct. 31, 2010, 875 of 11920 (7.3\%) in-flight emergencies resulted in a diversion. ${ }^{1}$ The most common causes of diversion included "syncope/presyncope" (25\%), "cardiac symptoms" (19\%), "seizures" (9\%), "respiratory symptoms" (9\%) and "possible stroke" (4\%). ${ }^{1}$ Other more serious complaints, although uncommon, resulted in a higher proportion of diversion rates. For example, only 38 cardiac arrests were recorded out of 11920 emergencies and of those, 22 (58\%) resulted in a diversion. ${ }^{1}$ Secondary considerations for aircraft diversion include availability of medical resources, runway and airport capabilities and geopolitical stability at the diversion point. The flight crew and ground-based medical support team will take into account all of these issues when considering a recommendation of diversion. It is important to note that the cost of a diversion is variable but has been estimated to be anywhere between $\$ 3000$ and almost $\$ 900000 .^{5,16}$ Ultimately, the captain of the aircraft is responsible for this decision and the overall safety of all passengers on board.

The role of medical volunteers is to manage the patient to the best of their ability and maintain open communication with the flight crew and ground-based consultant to ensure all parties are completely aware of the situation.

\section{Is there a legal and ethical duty for physicians to respond to in-flight medical emergencies?}

The Canadian Medical Association and Canadian Medical Protective Association have outlined the duties and responsibilities of physicians with respect to the risks of acting as a "Good Samaritan." There are two key aspects to consider when deciding whether to assist a fellow passenger during an in-flight medical emergency. The first is the ethical responsibility. According to the Canadian Medical Association Code of Ethics, physicians should

\section{Table 2: Routes of administration of injectable medications in the Air Canada and WestJet medical kits*}

\begin{tabular}{|c|c|c|}
\hline Medication & $\begin{array}{l}\text { Concentration } \\
\text { of ampule/vial }\end{array}$ & $\begin{array}{c}\text { Route(s) } \\
\text { of administration }\end{array}$ \\
\hline Atropine & $0.6 \mathrm{mg} / \mathrm{mL}$ & IV \\
\hline Dextrose $50 \%$ & $25 \mathrm{~g} / 50 \mathrm{~mL}$ & IV \\
\hline Diazepam & $10 \mathrm{mg} / 2 \mathrm{~mL}$ & IV or IM \\
\hline Dimenhydrinate & $250 \mathrm{mg} / 5 \mathrm{~mL}$ & IV or IM \\
\hline Diphenhydramine & $50 \mathrm{mg} / \mathrm{mL}$ & IV or IM \\
\hline Epinephrine 1:1000 & $1 \mathrm{mg} / \mathrm{mL}$ & IM† \\
\hline Furosemide & $40 \mathrm{mg} / 4 \mathrm{~mL}$ & IV or IM \\
\hline Haloperidol & $5 \mathrm{mg} / \mathrm{mL}$ & IV or IM \\
\hline Ketorolac & $30 \mathrm{mg} / \mathrm{mL}$ & IV or IM \\
\hline Lidocaine & $100 \mathrm{mg} / \mathrm{mL}$ & IV $\ddagger$ \\
\hline Methylprednisolone & $125 \mathrm{mg}$ & IV or IM \\
\hline \multicolumn{3}{|c|}{$\begin{array}{l}\text { Note: IM = intramuscular, IV = intravenous. } \\
\text { *Clinical discretion is advised, as the efficacy of the medication may vary depending on the chosen route of administration. Note that West Jet aircraft also carry prefilled syringe doses } \\
\text { of both atropine and epinephrine (1:10 000). } \\
\text { tThis concentration of epinephrine should be given only via the IM route unless the patient is in cardiac arrest. } \\
\text { tThis is the only pre-prepared medication and is meant for use as an antiarrhythmic during cardiac arrest. } \\
\text { Source: Adapted from information in the Air Canada medical kit. }\end{array}$} \\
\hline
\end{tabular}


"provide whatever appropriate assistance [they] can to any person with an urgent need for medical care." ${ }^{18}$ The second pertains to legal responsibility. According to the Canadian Medical Protective Association (CMPA):

In Canada, most jurisdictions do not impose a legal duty or obligation on physicians to provide emergency medical services. All jurisdictions, however, have legislation that protects physicians who voluntarily provide emergency assistance at the scene of an accident or in an emergency. Quebec is the only province in Canada that imposes a legal duty on physicians to come to the aid of a person in a life-threatening emergency. Quebec's Civil Code protects physicians from liability for that care. ${ }^{19}$

The CMPA states that physicians are "generally eligible for CMPA assistance" 19 in these situations and that "in emergency circumstances, members should focus on practising medicine to the best of their ability and in the best interests of the patient, confident that giving their utmost effort will be enough." ${ }^{19}$ According to the Aerospace Medical Association, although airlines have been sued for medical emergencies, no physician who has volunteered assistance has been known to be sued. ${ }^{9}$ The legal implications are challenging, because there is no international law outlining a physician's duty to respond. ${ }^{9}$ This is complicated by the fact that each jurisdiction will have differing laws and that airlines typically accept liability when they request a physician's assistance. ${ }^{9}$ Physicians should always check with their own medicolegal bodies as to what is expected and what coverage is available.

\section{References}

1. Peterson DC, Martin-Gill C, Guyette FX, et al. Outcomes of medical emergencies on commercial airline flights. N Engl J Med 2013;368:2075-83.

2. Air carrier traffic at Canadian airports: highlights. Ottawa: Statistics Canada; 2015. Cat no 51-203-X. Available: www.statcan.gc.ca/pub/51-203-x/2015000/ aftertoc-aprestdm1-eng.htm (accessed 2017 Jan. 12).

3. Shepherd B, Macpherson D, Edwards CM. In-flight emergencies: playing The Good Samaritan. J R Soc Med 2006;99:628-31.

4. Silverman D, Gendreau M. Medical issues associated with commercial flights. Lancet 2009;373:2067-77.
5. Ruskin KJ, Hernandez KA, Barash PG. Management of in-flight medical emergencies. Anesthesiology 2008;108:749-55.

6. Cocks R, Liew M. Commercial aviation in-flight emergencies and the physician. Emerg Med Australas 2007;19:1-8.

7. Valani R, Cornacchia M, Kube D. Flight diversions due to onboard medical emergencies on an international commercial airline. Aviat Space Environ Med 2010;81:1037-40.

8. Goodwin T. In-flight medical emergencies: an overview. BMJ 2000;321:1338-41.

9. Medical emergencies: managing in-flight medical events (guidance material for health professionals). Alexandria (VA): Aerospace Medical Association; 2016. Available: www.asma.org/publications/medical-publications-for-airline-travel/ managing-in-flight-medical-events (accessed 2017 Jan. 17).

10. Hinkelbein J. Significant more research required: no further progress without sound medical data and valid denominators for in-flight medical emergencies. $J$ Travel Med 2015;22:355-6.

11. Kesapli M, Akyol C, Gungor F, et al. Inflight emergencies during eurasian flights. $J$ Travel Med 2015;22:361-7.

12. Chapter 7: other medical concerns. In: Science and technology - fifth report. London (UK): House of Lords; 2000. Available: www.publications.parliament.uk/pa/ Id199900/ldselect/ldsctech/121/12112.htm\#a118 (accessed 2017 Jan. 20).

13. Division VI - emergency equipment. In: Part VII: Commercial air services. Ottawa: Transport Canada; 2016. Available: www.tc.gc.ca/eng/civilaviation/regserv/cars/ part7-standards-725-2173.htm\#725_91 (accessed 2017 Jan. 8).

14. Annex 6: Operation of aircraft, Part I: International commercial air transport aeroplanes. Chapter 6: Aeroplane instruments, equipment and flight documents. In: ICAO health related documents. Montréal: International Civil Aviation Organization; 2013 Available: www.icao.int/MID/Documents/2013/capsca-mid3/ ICAOHealthRelatedSARPsandguidelines.pdf (accessed 2017 Dec. 11).

15. Bishop LC. Aviation auscultation. JAMA 1990;263:233.

16. Gendreau MA, DeJohn C. Responding to medical events during commercial airline flights. N Engl J Med 2002;346:1067-73.

17. TP 12296: Flight attendant training standard. In: Initial part eight - aviation first aid. Ottawa: Transport Canada; 2013. Available: www.tc.gc.ca/eng/civilaviation /publications/tp12296-menu-1399.htm (accessed 2017 Jan. 8).

18. Canadian Medical Association Code of Ethics. Ottawa: Canadian Medical Association; 2015. Available: www.cma.ca/En/Pages/code-of-ethics.aspx (accessed 2017 Jan. 14).

19. Are there risks to acting as a good Samaritan? Ottawa: Canadian Medical Protective Association; 2015. Available: www.cmpa-acpm.ca/-/are-there-risks-to-acting-as-a -good-samaritan (accessed 2017 Jan. 14).

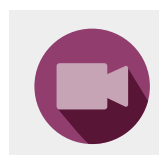
Please see the following video online:

Managing medical emergencies at 36000 feet: A guide to Air Canada's in-flight emergency medical Kit www.cmaj.ca/lookup/suppl/doi:10.1503/cmaj.170601/-/DC1
Competing interests: Ken Fryatt is the Medical Director for WestJet. Jim Chung is employed by Air Canada. No other competing interests were declared.

This article has been peer reviewed.

Affiliations: Division of Emergency Medicine, Department of Medicine (Kodama, Ackery); Division of Cardiac Surgery, Department of Surgery (Yanagawa), University of Toronto, Toronto, Ont.; Air Canada (Chung), Saint Lau- rent, Que.; WestJet Airlines Ltd. (Fryatt), Calgary, Alta.; St. Michael's Hospital (Yanagawa, Ackery), Toronto, Ont.; ORNGE Air Ambulance (Ackery), Toronto, Ont.

Contributors: David Kodama was the primary author, responsible for literature review, article design and synthesis of data and manuscript writing, including revisions. Alun Ackery was the senior corresponding author, responsible for article design and synthesis of data and manuscript writing, including revisions. Bobby Yanagawa, Jim Chung and Ken Fryatt participated in article design, content expertise and critical revisions. All of the authors gave final approval of the version to be published and agree to be accountable for all aspects of the work.

Correspondence to: Alun Ackery, ackerya@smh.ca 